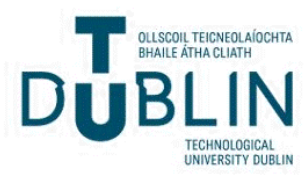

Technological University Dublin

ARROW@TU Dublin

2015-05-18

\section{Volatility and Risk Management in European Electricity Futures Markets}

Jim Hanly

Technological University Dublin, james.hanly@tudublin.ie

Lucia Morales

Technological University Dublin, lucia.morales@tudublin.ie

Follow this and additional works at: https://arrow.tudublin.ie/buschgraart

Part of the Finance and Financial Management Commons, and the Portfolio and Security Analysis Commons

\section{Recommended Citation}

Hanly, J. \& Morales, L. (2015) Volatility and Risk Management in European Electricity Futures Markets. Available at SSRN: https://ssrn.com/abstract=2607490, doi.org/10.2139/ssrn.2607490

This Working Paper is brought to you for free and open access by the Graduate Business School at ARROW@TU

Dublin. It has been accepted for inclusion in Articles by an authorized administrator of ARROW@TU Dublin. For more information, please contact

arrow.admin@tudublin.ie, aisling.coyne@tudublin.ie, gerard.connolly@tudublin.ie.

Funder: DIT 
Volatility and Risk Management in European Electricity Futures Markets Jim Hanly and Lucia Morales ${ }^{\mathrm{b}}$

a Jim Hanly,

Lecturer in Finance and

Research Fellow,

College of Business,

Dublin Institute of Technology,

Dublin 2,

Ireland.

Tel +353 14023180

E-mail james.hanly@dit.ie.

Corresponding Author.

bucia Morales,

Lecturer in Finance

College of Business,

Dublin Institute of Technology,

Dublin 2,

Ireland.

Tel +353 14023230 ,

E-mail lucia.morales@dit.ie. 


\title{
Volatility and Risk Management in European Electricity Futures Markets
}

\begin{abstract}
This paper estimates and applies a risk management strategy for electricity spot exposures using futures hedging. We apply our approach to three of the most actively traded European electricity markets, Nordpool, APXUK and Phelix. We compare both optimal hedging strategies and the hedging effectiveness of these markets for two hedging horizons, weekly and monthly using both Variance and Value at Risk (VaR). We find significant differences in both the Optimal Hedge Ratios (OHR's) and the hedging effectiveness of the different electricity markets. Better performance is found for the Nordpool market while the poorest performer in hedging terms is Phelix. However we also find that electricity futures hedging arerelatively ineffective as a risk management tool when compared with other energy assets. This isespecially true at the weekly frequency.
\end{abstract}

Keywords: Electricity, Energy; Futures; Hedging; Risk Management.

JEL classification: G10, G12, G15. 


\section{Introduction}

Following the deregulation and liberalisation of electricity markets in Europe a number of exchanges have developed to facilitate the trading of electricity. This process has resulted in the power companies shouldering the risk of adverse price movements as regulators no longer automatically allow them to transfer risk to their customers through price increases. In turn this has generated a demand for derivative products to allow for hedging those price risks. Hedging with futures contracts has become a standard way of managing commodity price risk, particularly with reference to energy markets, and standardised futures contracts are now traded on a number of power exchanges.

A large literature has documented the use and effectiveness of futures as a hedging tool since early work by Johnson (1960) and Ederington (1979). This literature has examined equities (Park and Switzer, 1995, Cotter and Hanly, 2006), various commodities (Lien and Yang, 2008, Wu, Guan, and Myers, 2011), foreign exchange (Brooks and Chong, 2001) portfolio products such as exchange traded funds (Alexander and Barbosa, 2008) and of course Energy commodities such as Crude Oil and its derivatives, (see for example, Switzer and El-Khoury, 2007,Chang, McAleer and Tansuchat, 2011) and Natural Gas (Root and Lien, 2003, Brinkmann and Rabinovich, 2005). The general results from the literature is that hedging is generally very effective as measured by risk reductions ${ }^{1}$ of the order of $60 \%-90 \%$ depending on the underlying asset being hedged. ${ }^{2}$

\footnotetext{
${ }^{1}$ A number of risk measures have been used in the literature as well as measures based on both risk and return however the variance is by far the most reported measure.

${ }^{2}$ Some assets have shown better hedging effectiveness, notably stock indices and certain oil contracts such as West Texas Intermediate.
} 
There has been relatively little work which has examined electricity price hedging using futures as the power exchanges are still relatively new ${ }^{3}$ and the European electricity marketsare not as liquid and deep as those of more established commodities markets such as oil. Another reason is that there are challenges associated with electricity spot price modelling given the characteristics of electricity prices such as high volatility and price spikes which arise because of non-storability and seasonality (Wickens and Wimschulte, 2007, Botterud, Kristiansen, and Ilic, 2010, Xiao, Colwell and Barr, 2014). One of the first papers to look at electricity futures hedging was Tanlapco, Lawarrée and Liu (2002). They looked at both cross and direct hedging using data from the US electricity market. They estimated OHR's in the range 0.25 to 1.35 and found a significant difference between the Naïve hedge ratio and the OHR as estimated using OLS. They found reductions in risk as measured by the standard deviation ranging from about $3 \%$ up to a maximum of $38 \%$ depending on the market being hedged. Bystrom (2003) looked at hedging in the Nordpool market using weekly data, for the period $1996-1999$. He found that hedging effectiveness from Naïve ${ }^{4}$, OLS and GARCH models was typically of the order of $10 \%-20 \%$. Zanotti, Gabbi and Geranio (2010) use similar methods to analyse hedging for Nordpool, Phelix and Powernext markets. Their findings which are based on daily data indicate that model choice has a significant impact on hedging efficiency. They also find that daily hedges are relatively ineffective with typical variance reductions of around $2 \%-3 \%$.Frestad (2012) also analyses hedging in the Nordpool market but uses a more extensive dataset ranging from 2000 2010. Using an OLS model and a moving window to allow for time variationhe

\footnotetext{
${ }^{3}$ Two of the most active exchanges in Europe are Nordpool which was established in 1996, the European Energy Exchange which was established in 1999 and Amsterdam Power Exchange United Kingdom which was established in 2000 .

${ }^{4}$ This is a $1: 1$ hedge ratio.

${ }^{5}$ For specific period or models hedging effectiveness was as high as $29 \%$ but was also ineffective in certain cases where hedging increased the variance.
} 
documents relatively poor performance using a measure based on accumulated gain but notes that this may relate to ambiguity about the goals of a hedging strategy whereby risk minimisation may not be the main objective.More recently Sanda, Olsen, and Fleten, (2013) look at company level hedging for hydro based electricity companies and find that over $90 \%$ of aggregate production is hedged. They use cash flow at risk rather than the variance as their measure of hedging efficacy and find that only one of twelve companies showed a significant reduction in monthly cash flow variance.

Given the lack of depth in terms of coverage we address some issues that are pertinent to electricity hedging.We contribute to the literature on electricity markets by analysing the volatility and hedging characteristics of three of the most liquid European electricity markets, Nordpool, Phelix and APXUK using a dataset stretching from 2004 to 2014. We apply both constant and time varying methodologies for two time horizons, weekly and monthly, to allow us to track how OHR's and hedging effectiveness have changed as the markets have developed through both tranquil and intensely volatile periods. This paper also makes a contribution by drawing comparisons from the broader hedging and energy hedging literatures using both the commonly applied variance reduction criterion as well a down side risk measure $-\mathrm{VaR}$, to account for non-normality. Finally we look at whether model choice matters in terms of hedging effectiveness.

Our results indicate that there are significant differences in both the OHR's and hedging effectiveness of the three electricity markets. The choice of hedging time horizon also has an important impact of the efficacy of hedging strategies with hedges at the monthly frequency significantly outperforming weekly hedges. More 
generally the results indicate electricity market participants can obtain only relatively small risk reductions through the use of futures hedging. This is particularly true of the Phelix market at the weekly frequency. We now outline the hedging models used in this paper.

\section{Hedging Models}

There are a number of frameworks that can be used to examine optimal hedging. The most generally applied is the variance minimisation framework (see for example, Ederington, 1979) which assumes that futures prices are martingale and hence ignores the return component of a hedged portfolio. In this framework the OHRis the ratio of futures relative to spot that minimises the variance of the hedged portfolio. Other papers have incorporated expected return into the estimation of the optimal hedge via utility maximisation (Kroner and Sultan, 1993, deVille deGoyet, Dhaene and Sercu, 2008, Cotter and Hanly, 2012). This allows a number of different characterisations of investor utility to be applied. In this paper we adopt the variance minimisation approach given the widespread use of the variance as a risk measure; its dominance in the hedging literature and its twin advantages of relative ease of calculation and interpretation. It also allows us to draw comparisons between the hedging effectiveness of electricity futures and the hedging effectiveness of other energy assets which many papers (see for example, Switzer and El-Khoury, 2007, Alexander, Prokopczuk and Sumawong, 2013) have examined using the variance minimisation paradigm. 
We use two methods to estimate the OHR.The first model we use is an OLS regression based hedge which yields a constant hedge ratio over the period for which it is estimated. This is given by:

$$
r_{s t}=\alpha+\beta r_{f t}+\varepsilon_{t}
$$

where $r_{s t}$ and $r_{f t}$ are the spot and futures returns respectively for period t. The OLS model has been extensively used since it was first introduced by Johnson (1960); however it assumes a constant variance despite evidence that many economic time series are heteroskedastic. GARCH models address this issue by allowing the conditional distribution of spot and futures returns to vary over time. Therefore, the second model we use is the Constant Correlation or CCGARCH model introduced by Bollerslev (1990). This model has been applied extensively in a hedging context, is easy to estimate and provides good estimation characteristics even for relatively small samples ${ }^{6}$.The model is specified as follows:

$$
\begin{aligned}
& y_{t}=E\left(y_{t} \mid F_{t-1}\right)+\varepsilon_{t}, \varepsilon_{t}=D_{t} \eta_{t} \\
& \operatorname{var}\left(\varepsilon_{t} \mid F_{t-1}\right)=D_{t} R D_{t}
\end{aligned}
$$

where $y_{t}=\left(y_{1 t} \ldots y_{m t}\right)^{\prime}, \quad \eta_{t}=\left(\eta_{1 t} \ldots \eta_{m t}\right)^{\prime}$ is a sequence of independent and identically distributed random vectors, $F_{t}$ is the information set at time t, $D_{t}=\operatorname{diag}\left(h_{1}^{1 / 2}, \ldots h_{m}^{1 / 2}\right)$, $m$ is the number of returns and $t=1 \ldots n . R=E\left(\eta_{t} \eta_{t}^{\prime} \mid F_{t-1}\right)=\left(\eta_{t} \eta_{t}^{\prime}\right)$ where $R=\rho_{i j}$ for $i, j=1, \ldots, m \cdot \varepsilon_{t} \varepsilon_{t}^{\prime}=D_{t} \eta_{t} \eta_{t}^{\prime} D_{t} D_{t}=\left(\operatorname{diag} Q_{t}\right)^{1 / 2}$ and $E\left(\varepsilon_{t} \varepsilon_{t}^{\prime} \mid F_{t-1}\right)=Q_{t}=D_{t} R D_{t}$ where $\quad Q_{t}$ is the conditional covariance matrix. The model assumes that conditional correlations are constant and therefore the conditional covariances are proportional to the product of the corresponding conditional standard deviations. Each of the conditional variances in $D_{t}$ has a univariate $\mathrm{GARCH}(1,1)$ specification.

\footnotetext{
${ }^{6}$ This is importance where monthly data is being used as there are relatively few data points.
} 


$$
h_{i t}=\omega_{i}+\sum_{j=1}^{r} \alpha_{i j} \varepsilon_{i}^{2},_{t-j}+\sum_{j=1}^{s} \beta_{i j} h_{i, t-j}
$$

\section{$3 \quad$ Risk Measures}

We use two risk measures to compare the effectiveness of the OLS and CCGARCH hedge strategies. The first risk measure is the variance and the hedging effectiveness is measured as the percentage reduction in the variance of a hedged portfolio as compared with the variance of an unhedged portfolio which is simply the unhedged spot return.

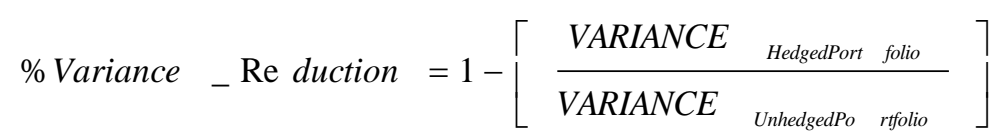

Despite is broad ranging use, there are problems with the Variance as a risk measure, chief of which is that it cannot differentiate between upside and downside risk as it gives equal weight to positive and negative returns. Given that electricity time series are non-normal as evidenced by skewness and kurtosis characteristics we have also included a downside risk metric to measure hedging effectiveness. There are a number of risk metrics that have the ability to measure risk in one tail of the distribution including Lower Partial Moments, Semi Variance and Expected Shortfall, however we have chosen to use VaR given its broad application in the regulatory framework, ease of estimation and intuitive interpretation. VaR estimates the maximum expected loss for a given confidence level and for a specified time period. ${ }^{7}$ The VaR at confidence level $\alpha$ is

$$
\operatorname{VaR}_{\alpha}=q_{a}
$$

${ }^{7}$ For more detail on VaR, see Jorien 2006. We calculate VaR at the 5\% level. For the use of VaR in a hedging context see Harris and Shen, 2006 
Where $q_{a}$ is the quantile of the loss distribution.We calculate VaR using the $5 \%$ confidence level under which we would expect losses in excess of the VaR to occur once every 20 days. The performance metric employed is the percentage reduction in VaR.

$$
\% \text { VaR_Re duction }=1-\left[\frac{V a R_{5 \% \text { HedgedPort folio }}}{V a R_{5 \% \text { UnhedgedPo }} \text { rffolio }}\right]
$$

\section{$4 \quad$ Data}

Electricity markets are very different from other energy commodities markets essentially because of the non-storability of electricity. Spot markets for electricity are generally managed by Power Exchanges and prices are set by a process whereby bids are submitted by market participants for the day following the bid process. Equilibrium is established and a market clearing price is set for the following day and for this reason, spot markets are in effect day ahead markets. Electricity spot prices exhibit a number of key characteristics including volatility clustering, seasonality $^{8}$, mean reversion and price jumps or spikes. Some of these characteristics present a unique challenge in terms of obtaining an efficient hedging solution to electricity price risk.

In this paper we are seeking to determine the efficacy of hedging as a risk management strategy for electricity market participants. Our analysis is also focused on the volatility characteristics of the European electricity futures marketsand the evolution of these markets which are still quite new as compared with longer established energy commodity markets. We therefore choose three different contracts to represent three different markets. The markets used are Nordpool for

\footnotetext{
${ }^{8}$ The demand and supply characteristics of the electricity market can change rapidly and therefore seasonal factors such as time of day, calendar, weather, economic activity will all have an impact. Because these factors are time dependent the frequency of the data will have an important impact on the price behavior.
} 
Scandinavia, European Energy Exchange for Germany (Phelix) and Amsterdam Power Exchange (APX) UK for the United Kingdom. These were chosen given their liquidity and because they are some of the most long standing electricity futures contracts available.In each case we obtained day-ahead auction prices which we use as spot prices ${ }^{9}$. For the futures contracts we used base load average reference prices for which a continuous series was formed we used a rollover process. Our full sample is for a 10 year period and includes data from 15/09/2004 to 10/01/2014.We initially include data at three different frequencies; daily (1-day), weekly (5-day) and monthly (20-day) to allow for a broad ranging analysis that reflects the time horizons of different market participants.Figure 1 provides a time series plot of prices, returns and volatility ${ }^{10}$ for each of the electricity series we examine. Descriptive statistics are given in Table 1. Many of the stylised facts around electricity prices are clearly shown from Figure 1, including volatility clustering, price jumps, and mean reversion. We can also observe that the volatility varies over time.

Each series displays a positive mean for the period under study. The electricity data also shares many of the same characteristics of other energy series such as the presence of significant Skewness and Kurtosis. The Jarque-Bera (J-B) statistic indicatesthat each of the series is non-normal but also that departures from normality are more pronounced for higher frequency data. Indeed the descriptive statistics in general show that electricity spot prices tend to be much more volatile and have larger departures from normality than other energy assets such as Oil. For example,

\footnotetext{
${ }^{9}$ The spot market for physical delivery of electricity is different than for other commodity markets and is based on an auction system that matches bids with generation and sets a price for market participants 24 hours prior to the delivery. Therefore spot prices are in effect a day ahead futures contract. See the following for more detailed information:

http://www.apxgroup.com/trading-clearing/apx-power-uk/ http://www.nordpoolspot.com/How-does-it-work/Day-ahead-market-Elspot-/ https://www.eex.com/en/products/power/power-derivatives-market
} 
weekly standard deviations are in the range $15 \%$ to $30 \%$ as compared with a typical weekly standard deviation for crude oil of about $5 \%$. This presents a particular challenge from a hedging perspective. Unit root tests indicate that all series are stationary while we also find the presence of significant $\mathrm{ARCH}$ effects in most cases. Also of interest is that the while the correlation between spot and futures prices ranges from $70 \%$ to $90 \%$ depending on the electricity market, the attendant returns show much lower correlation. We also note that the correlations are higher at lower frequency indicating that hedging performance should be significantly better for lower frequency hedges. Indeed the extremely low correlations for daily returns indicate that hedging will be largely ineffective at this frequency.

\section{Hedging Estimation}

Our in-sample data ranges from 14/09/2005 to 05/09/2012. For this period we estimated a constant hedge ratio using OLS and a time-varying hedge ratio using the CCGARCH model. The spot return was then hedged using the following

$$
+r_{s t}-\beta r_{f t}
$$

where $r_{s}$ and $r_{f}$ are spot and futures returns respectively, and $\beta$ is the OHR.In this way we generated1825 t-period hedges in-sample at the daily frequency, 365 at the weekly frequency and 92 at the monthly frequency for the period October 2005 to December 2012.These were formed into a single portfolio on which we based our hedging effectiveness estimates. We also retained a subsample of two years of data for the period 12/09/2012 to 01/10/2014 for out-of-sample testing. This was done by generating 1-step ahead forecasts of the OHR for use in period $t+1$. The OHR's were assumed tofollow a random walk process and the 1-step-ahead forecasts for the time varying hedges were generated using a rolling window approach. Because we 
also wish to track how hedging effectiveness changed over time, we carried out an additional estimation based on a rolling window OLS model. The initial OHR was estimatedusing a window length equivalent to one year of data for the period October 2004 to October 2005. The hedging effectiveness was then estimated for a portfolio of hedged returns using the $\%$ reduction in the variance criterion before rolling the window forward. This was done by adding an observation and removing the oldest observation thus keeping the window length unchanged. The process was then repeated. 

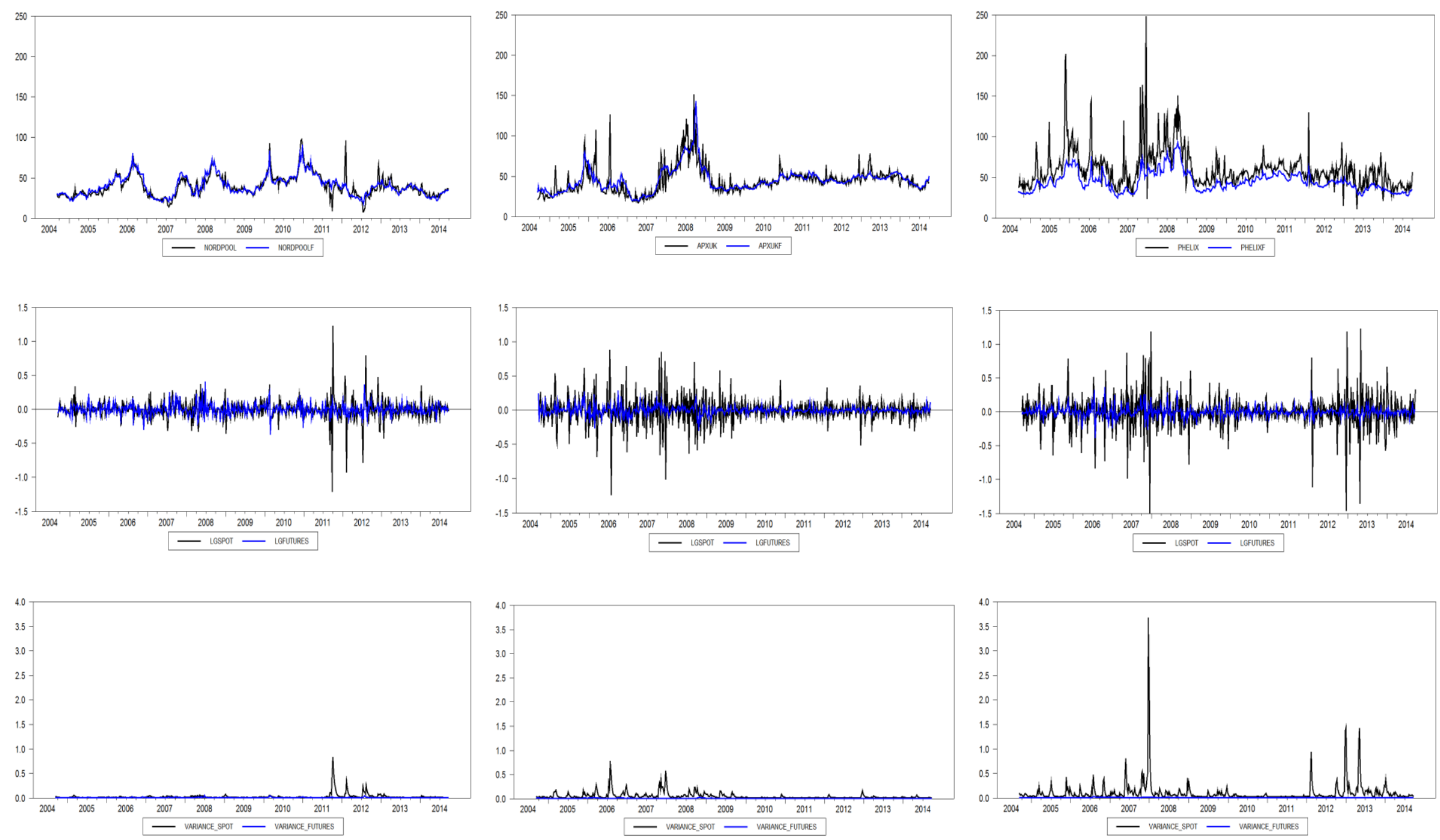

Fig1. Price, Returns and Volatility of NORDPOOL, APXUK AND PHELIX Electricity Spot and Futures using Weekly data. 
Table 1 Descriptive Statistics

\begin{tabular}{|c|c|c|c|c|c|c|c|c|c|c|c|c|c|}
\hline & \multirow[t]{2}{*}{ Index } & \multirow{2}{*}{$\begin{array}{c}\text { Mean } \\
\%\end{array}$} & \multirow{2}{*}{$\frac{\text { Std Dev }}{\%}$} & \multirow[t]{2}{*}{ Skewness } & \multirow[t]{2}{*}{ Kurtosis } & \multirow[t]{2}{*}{ JB } & \multirow[t]{2}{*}{ LM } & \multicolumn{4}{|c|}{ STATIONARITY } & \multicolumn{2}{|c|}{ Correlation } \\
\hline & & & & & & & & \multirow[t]{2}{*}{ ADF } & $\mathbf{P P}$ & \multicolumn{2}{|c|}{ KPSS } & \multirow[t]{2}{*}{ Price } & \multirow[t]{2}{*}{ Returr } \\
\hline NORDPOOL & & & & & & & & & & CONSTANT & TREND & & \\
\hline \multirow{2}{*}{ DAILY } & Spot & 0.0063 & 7.87 & $0.30 *$ & $11.20 *$ & $13730.8 *$ & $212.8^{*}$ & $-24.1 *$ & $-53.7^{*}$ & 0.010 & $0.008^{*}$ & 0.900 & 0.09 \\
\hline & Futures & 0.0052 & 3.51 & $1.27 *$ & $17.08^{*}$ & $32541.9 *$ & 5.0 & $-23.6^{*}$ & $-48.1^{*}$ & $0.032 *$ & $0.022 *$ & & \\
\hline \multirow[t]{2}{*}{ WEEKLY } & Spot & 0.0314 & 15.53 & $-0.28 *$ & $19.11^{*}$ & $7976.5^{*}$ & $84.2 *$ & $-9.2 *$ & $-26.0 *$ & $0.016^{*}$ & $0.012 *$ & 0.894 & 0.28 \\
\hline & Futures & 0.0262 & 8.19 & $0.34 *$ & $3.52 *$ & $280.0^{*}$ & $32.3^{*}$ & $-26.0^{*}$ & $-24.1^{*}$ & $0.039 *$ & $0.026^{*}$ & & \\
\hline \multirow[t]{2}{*}{ MONTHLY } & Spot & 0.5776 & 29.34 & $0.38 *$ & $11.22 *$ & $638.1 *$ & $33.9 *$ & $-5.8 *$ & $-16.6^{*}$ & $0.057 *$ & $0.028 *$ & 0.8957 & 0.49 \\
\hline & Futures & 0.0702 & 15.83 & $-0.38 *$ & $2.12 *$ & $25.5^{*}$ & 7.2 & $-5.8 *$ & $-10.9^{*}$ & $0.033^{*}$ & $0.030^{*}$ & & \\
\hline \multicolumn{14}{|l|}{ APXUK } \\
\hline \multirow[t]{2}{*}{ DAILY } & Spot & 0.0268 & 15.47 & $0.32 *$ & $6.39 *$ & $4496.8^{*}$ & $149.2 *$ & $-31.7^{*}$ & $-78.6^{*}$ & $0.009 *$ & $0.005^{*}$ & 0.8020 & 0.16 \\
\hline & Futures & 0.0201 & 2.75 & $2.17 *$ & $24.76^{*}$ & $68997.8 *$ & $47.3^{*}$ & $-23.8^{*}$ & $-48.1^{*}$ & $0.051 *$ & $0.043^{*}$ & & \\
\hline \multirow[t]{2}{*}{ WEEKLY } & Spot & 0.1339 & 20.99 & $-0.31 *$ & $5.38 *$ & $640.5^{*}$ & $45.8^{*}$ & $-14.5^{*}$ & $-36.6^{*}$ & $0.029 *$ & $0.015^{*}$ & 0.8010 & 0.28 \\
\hline & Futures & 0.1003 & 6.09 & $0.26^{*}$ & $4.93 *$ & $536.7 *$ & $54.3^{*}$ & $-7.5^{*}$ & $-22.8^{*}$ & $0.043^{*}$ & $0.036^{*}$ & & \\
\hline \multirow[t]{2}{*}{ MONTHLY } & Spot & 1.8892 & 25.72 & $0.54 *$ & $6.42 *$ & $213.6^{*}$ & 14.0 & $-4.3 *$ & $-16.7^{*}$ & $0.263^{*}$ & $0.055^{*}$ & 0.8250 & 0.38 \\
\hline & Futures & 0.4499 & 13.18 & $-0.66^{*}$ & $3.88^{*}$ & $84.5^{*}$ & $33.7 *$ & $-4.9 *$ & $-8.1 *$ & $0.047^{*}$ & $0.033^{*}$ & & \\
\hline \multicolumn{14}{|l|}{ EEX PHELIX } \\
\hline \multirow[t]{2}{*}{ DAILY } & Spot & 0.0151 & 23.33 & -0.05 & $13.97 *$ & $21312.5^{*}$ & $575.3^{*}$ & $-31.8^{*}$ & $-84.0 *$ & $0.004 *$ & $0.003^{*}$ & 0.7110 & 0.07 \\
\hline & Futures & 0.0029 & 3.32 & $2.07 *$ & $38.43^{*}$ & $163061.6^{*}$ & 9.2 & $-22.8 *$ & $-49.6^{*}$ & $0.042 *$ & $0.019 *$ & & \\
\hline \multirow[t]{2}{*}{ WEEKLY } & Spot & 0.0756 & 29.34 & $-1.17^{*}$ & $11.93^{*}$ & $3227.3 *$ & $59.7 *$ & $-14.4^{*}$ & $-40.6^{*}$ & $0.015^{*}$ & $0.011^{*}$ & 0.7431 & 0.29 \\
\hline & Futures & 0.0146 & 7.56 & $0.49 *$ & $5.21 *$ & $613.2 *$ & $28.0 *$ & $-11.1^{*}$ & $-23.4^{*}$ & $0.044 *$ & $0.020 *$ & & \\
\hline \multirow[t]{3}{*}{ MONTHLY } & Spot & 1.6047 & 36.73 & $0.27 *$ & $4.31 *$ & $95.0^{*}$ & $31.5^{*}$ & $-6.3^{*}$ & $-19.4^{*}$ & $0.341 *$ & $0.054^{*}$ & 0.7568 & 0.41 \\
\hline & Futures & 0.1281 & 15.41 & -0.12 & 0.24 & $0.6^{*}$ & 12.7 & $-4.9 *$ & $-12.0^{*}$ & $0.058^{*}$ & $0.030 *$ & & \\
\hline & $1 \%$ C.V & & & & & 9.21 & 13.23 & -3.43 & -3.43 & 0.74 & 0.22 & & \\
\hline
\end{tabular}

Note: Descriptive statistics are presented for the log returns of each spot and futures series. The mean and standard deviation (Stdev) are in percentages. The total sample period runs from 15/09/2004 until 01/10/2014.Weekly returns are 5-day while monthly returns are 20-day. JB is the Jarque-Bera statistic which measures normality. LM, (with 4 lags) is the Engle (1982) ARCH test for heteroskedasticity. ADF is the augmented dickey fuller test (with 4 lags) for stationarity. PP is the Philips Peron test for stationarity.Stationarity is also tested using the Kwiatkowski, Phillips, Schmidt and Shin (KPSS) test which tests the null of stationarity against the alternative of a unit root.The correlation coefficient between each set of cash and futures is also given for both price and log returns. $*$ denotes significance at the $1 \%$ level. 


\section{Empirical Findings}

\section{Volatility}

Results of our volatility analysis are presented in Table 2, while Figure 2 provides more resolution for the volatility graphs obtained from fitting a $\mathrm{GARCH}(1,1)$ to the electricity return series. The most obvious difference is the large difference in the magnitude of volatility between spot and futures markets. For other energy assets these would typically mirror each other however for electricity the spot volatility is notably higher for the reasons discussed earlier. In terms of a comparison, some differences emerge across the different spot series, most notably that the Nordpool series is the least volatile, followed by APXUK and PHELIX. Differences in spot volatility probably reflect the production structure and generational fuel mix in each market ${ }^{11}$. For the futures series the volatility between the markets is broadly similar.
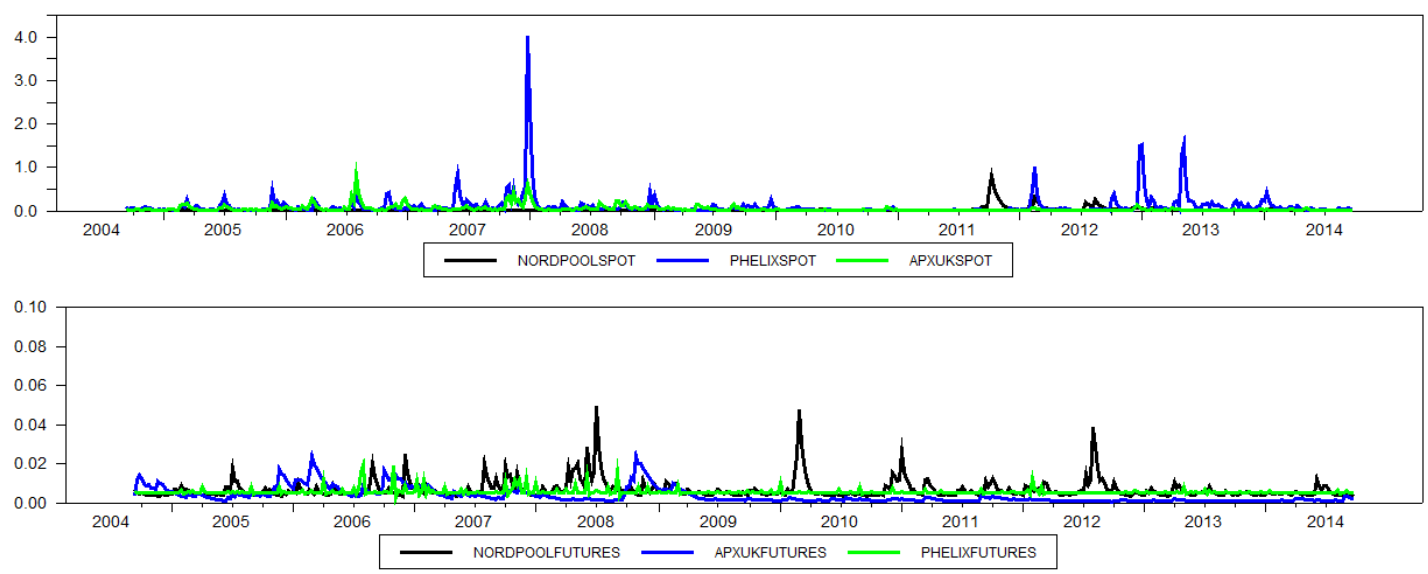

Fig2. Volatility of NORDPOOL, APXUK AND PHELIX Electricity Spot and Futures using Weekly data. Note the Spot and Futures are to difference scales.

\footnotetext{
${ }^{11}$ For example, the Norway has a very large hydro generation capacity which is very flexible whereas the German market has relied on both Nuclear and more recently Coal fired generation which in less flexible and therefore more prone to spikes.
} 


\begin{tabular}{|c|c|c|c|c|c|c|}
\hline Market & Frequency & & $\omega$ & $\alpha$ & $\beta$ & $\alpha+\beta$ \\
\hline & & & & & & Volatility \\
\hline & & & & & & Persistence \\
\hline \multirow[t]{6}{*}{ NORDPOOL } & DAILY & Spot & 0.0004 & 0.331 & 0.653 & 0.984 \\
\hline & & Futures & 0.0003 & 0.068 & 0.907 & 0.975 \\
\hline & WEEKLY & Spot & 0.0021 & 0.329 & 0.610 & 0.939 \\
\hline & & Futures & 0.0017 & 0.236 & 0.525 & 0.761 \\
\hline & MONTHLY & Spot & 0.0511 & 0.212 & 0.105 & 0.317 \\
\hline & & Futures & 0.0156 & 0.382 & 0.003 & 0.385 \\
\hline \multirow[t]{6}{*}{ APXUK } & DAILY & Spot & 0.0014 & 0.241 & 0.726 & 0.967 \\
\hline & & Futures & 0.0003 & 0.273 & 0.718 & 0.991 \\
\hline & WEEKLY & Spot & 0.0049 & 0.410 & 0.537 & 0.947 \\
\hline & & Futures & 0.0001 & 0.142 & 0.841 & 0.983 \\
\hline & MONTHLY & Spot & 0.0031 & 0.173 & 0.782 & 0.955 \\
\hline & & Futures & 0.0005 & 0.296 & 0.701 & 0.997 \\
\hline \multirow[t]{6}{*}{ EEX PHELIX } & DAILY & Spot & 0.0029 & 0.292 & 0.695 & 0.987 \\
\hline & & Futures & 0.0004 & 0.046 & 0.560 & 0.606 \\
\hline & WEEKLY & Spot & 0.0118 & 0.602 & 0.394 & 0.996 \\
\hline & & Futures & 0.0002 & 0.066 & 0.909 & 0.975 \\
\hline & MONTHLY & Spot & 0.0010 & 0.128 & 0.823 & 0.951 \\
\hline & & Futures & 0.0011 & 0.129 & 0.824 & 0.953 \\
\hline
\end{tabular}

Table 2: Volatility

Note: Volatility is measured as the unconditional volatility estimated using $\omega_{i} / 1(-\alpha-\beta)$ from a univariate GARCH $(1,1)$ process as in equation: $h_{i t}=\omega_{i}+\sum_{j=1}^{r} \alpha_{i j} \varepsilon_{i}{ }^{2},{ }_{t-j}+\sum_{j=1}^{s} \beta_{i j} h_{i, t-j}$. The sum of $\alpha+\beta$ measures volatility persistence. The model was run constraining $\alpha+\beta \leq 1$ which is equivalent to an IGARCH specification to avoid explosive volatility

The coefficients from the Garch $(1,1)$ model for electricity are quite different from those typically found at the daily, weekly and monthly frequencies for other energy assets such as Oil or Natural Gas. For example, volatility persistence is very high not only at the daily frequency but also at weekly and monthly frequencies. Only the Nordpool series displays a volatility persistence structure that is similar to other energy assets with persistence declining as the time horizon lengthens whereas for both APXUK and PHELIX the volatility persistence remains very high at weekly and monthly frequencies. These results are in line with the stylised facts for electricity 
markets and are similar to those foundby other studies such as (Gianfreda, 2010).We now go on to look at the results from the hedging models.

\section{Optimal Hedges}

Figure 3 presents the OHR's for each of the three markets examined for both weekly and monthly data. The first thing to note is the volatility of the CCGARCH OHR's for each market but especially for the weekly hedges. For example the Phelix market has an OHR which exceeds three on a number of occasions and goes as high as 8.9.
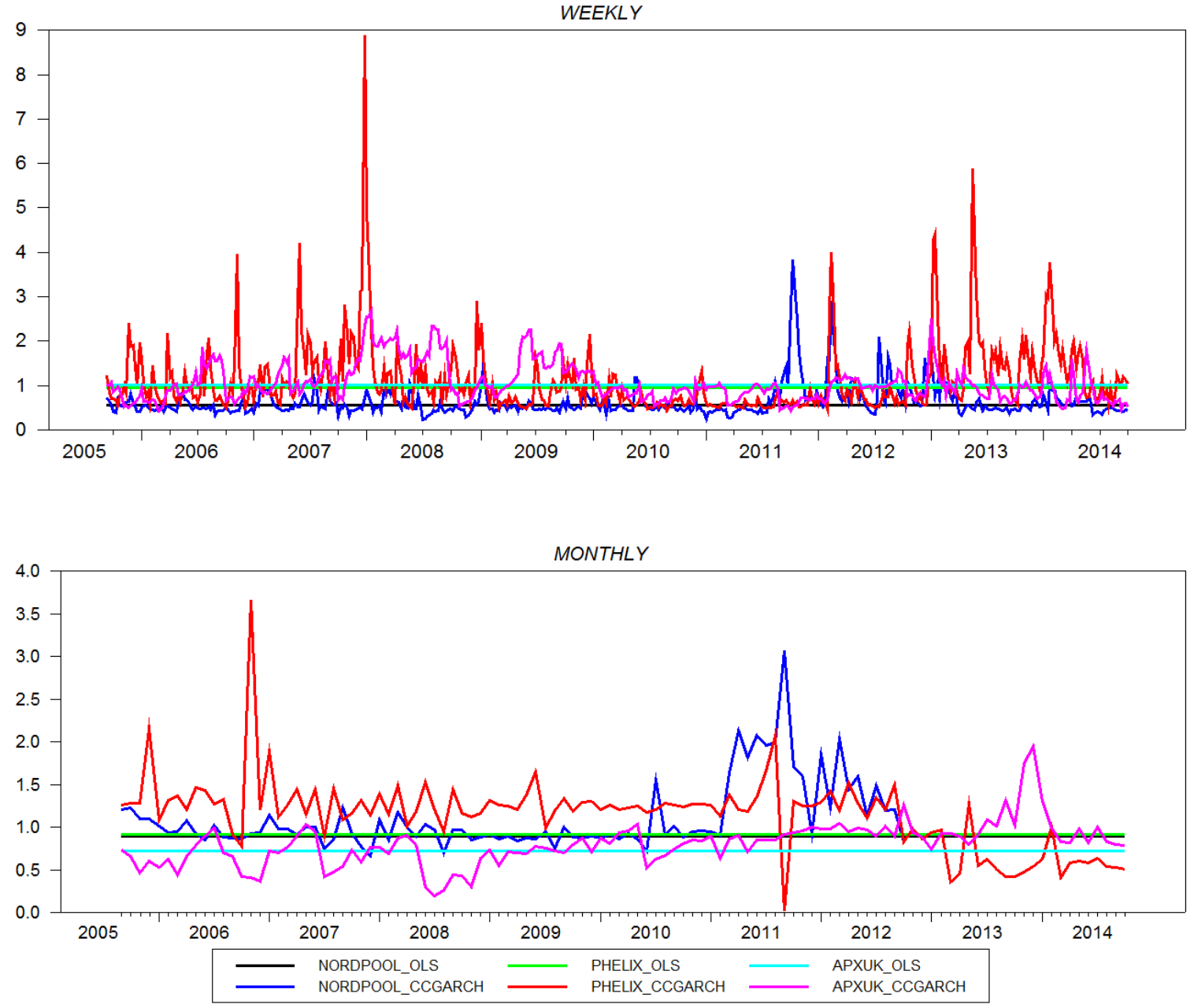

Fig 3. OHR's, OLS AND CCGARCH for NORDPOOL, APXUK and PHELIX markets. 
For monthly data the time-varying hedges are somewhat lower but are still large in comparison to those obtained from other energy assets such as Oil or Natural Gas which typically have OHRs in the range 0.5 to 1.5 (Cotter and Hanly, 2012). The second thing to note is the difference between the OHR's for the different markets. For example at the weekly (monthly) frequency the OLS based OHR's are 0.56 (0.89) for Nordpool, 1.02 (0.72 for APXUK and 0.94 (0.92) for Phelix. These results reflect the different volatility and correlation dynamics between spot and futures for the different markets.

\section{Hedging Effectiveness}

In this paper we sought to establish the hedging effectiveness of futures hedging strategies for electricity market participants in Europe and to make inter market comparisons to see whether any large differences emerged. Accordingly, Table 3 shows in-sample results for the three electricity markets we examine; Nordpool, APXUK and Phelix. Two risk measures, Variance and VaR are presented together with the attendant percentage reduction in those risk measures using two frequencies, Weekly and Monthly. Although estimated, we do not present detailed results for Daily hedges as hedging effectiveness was extremely poor in all cases averaging about $1.3 \%$ across all assets ${ }^{12}$. This is comparable to results for daily hedges found by Zanotti, Gabbi and Geranio (2010).

From Table 3, the most striking thing is that hedging effectiveness is quite low for each of the electricity markets and especially so at the weekly frequency. Taking the best performing model for each market for example, hedging effectiveness as

\footnotetext{
${ }^{12}$ Results for the daily hedges are available on request.
} 
measured by variance reduction ranges from $8.03 \%$ for Phelix to $8.19 \%$ for APXUK and $8.77 \%$ for the best performer which is Nordpool. Using the VaR criterion, the results are even poorer with reductions ranging from $4.11 \%$ (Phelix) to $4.52 \%$ (Nordpool).To put this in economic terms, for an exposure in the electricity market of $€ 1$ million, for the best performer which is Nordpool, hedging would reduce the VaR from $€ 395,288$ to $\$ 377,892$ - a reduction of just $€ 17,396$. These results are worse than those reported by Bystrom (2003)who found weekly hedging efficiency of about $17 \%$ for the Nordpool market. However we examine a much larger time period and two additional markets. Moving on to look at hedges with a monthly time horizon, the results are significantly better with hedging effectiveness for the best performing model ranging from $17.77 \%$ for the APXUK hedges to $24.02 \%$ for Phelix and $27.37 \%$ for Nordpool which again is the best performing market.VaR reductions are also improved but are still quite low. For example the best hedging performance using VaR is in the Nordpool market (15.39\%) while the worst is APXUK (9.02\%). The results from VaR which is a tail specific measure indicate that the volatility and nonnormality of electricity data presents a particular challenge in terms of obtaining a good hedging outcome. In terms of a comparison with other energy assets electricity hedges perform very poorly. Typical hedging effectiveness for Crude Oil is in the range $55 \%$ to $80 \%{ }^{13}$ and for Natural Gas about $53 \%$ to $83 \%{ }^{14}$.

\footnotetext{
${ }^{13}$ See for example Chang, McAleer and Tansuchat, R., (2011)who base their study on daily data.

${ }^{14}$ See for example Cotter and Hanly (2012). $53 \%$ is for weekly and $83 \%$ for monthly hedges.
} 


\begin{tabular}{|c|c|c|c|c|c|c|c|}
\hline & & 1 & 2 & 3 & 4 & 5 & 6 \\
\hline & & \multicolumn{3}{|c|}{ WEEKLY } & \multicolumn{3}{|c|}{ MONTHLY } \\
\hline & & NO HEDGE & OLS & CCGARCH & NO HEDGE & OLS & CCGARCH \\
\hline \multirow[t]{4}{*}{ NORDPOOL } & VARIANCE & $2.88 \%$ & $2.63 \%$ & $2.64 \%$ & $10.20 \%$ & $7.69 \%$ & $7.41 \%$ \\
\hline & VaR & $-€ 395,288$ & $-€ 377,439$ & $-€ 377,892$ & $-€ 742,901$ & $-€ 646,834$ & $-€ 628,562$ \\
\hline & $\%$ Variance Reduction & $0.00 \%$ & $8.77 \%^{\wedge}$ & $8.40 \%^{\wedge}$ & $0.00 \%$ & $24.65 \% *$ & $27.37 \%$ \\
\hline & $\%$ VaR Reduction & $0.00 \%$ & $4.52 \%{ }^{\lambda}$ & $4.40 \%^{\lambda}$ & $0.00 \%$ & $12.93 \% *$ & $15.39 \%$ \\
\hline \multirow[t]{4}{*}{ APXUK } & VARIANCE & $5.36 \%$ & $4.92 \%$ & $5.03 \%$ & $6.76 \%$ & $5.58 \%$ & $5.56 \%$ \\
\hline & VaR & $-€ 538,258$ & $-€ 515,979$ & $-€ 524,230$ & $-€ 603,683$ & $-€ 549,238$ & $-€ 551,779$ \\
\hline & $\%$ Variance Reduction & $0.00 \%$ & $8.19 \% *^{\lambda}$ & $6.17 \%^{\lambda}$ & $0.00 \%$ & $17.51 \%$ & $17.77 \%$ \\
\hline & \% VaR Reduction & $0.00 \%$ & $4.14 \% *^{\lambda}$ & $2.61 \%^{\lambda}$ & $0.00 \%$ & $9.02 \%$ & $8.60 \%$ \\
\hline \multirow[t]{4}{*}{ PHELIX } & VARIANCE & $7.77 \%$ & $7.15 \%$ & $7.79 \%$ & $9.79 \%$ & $7.44 \%$ & $9.81 \%$ \\
\hline & VaR & $-€ 648,492$ & $-€ 621,841$ & $-€ 650,505$ & $-€ 735,341$ & $-€ 641,252$ & $-€ 720,118$ \\
\hline & $\%$ Variance Reduction & $0.00 \%$ & $8.03 \%^{*^{\Lambda}}$ & $-0.19 \%$ & $0.00 \%$ & $24.02 \% *$ & $-0.15 \%$ \\
\hline & $\%$ VaR Reduction & $0.00 \%$ & $4.11 \% * \dagger$ & $-0.31 \%$ & $0.00 \%$ & $12.80 \% *$ & $2.07 \%$ \\
\hline
\end{tabular}

\section{Table 3: In Sample Hedging}

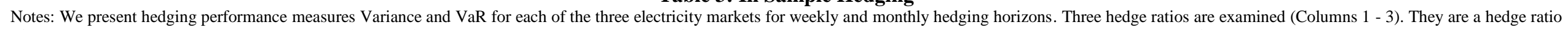

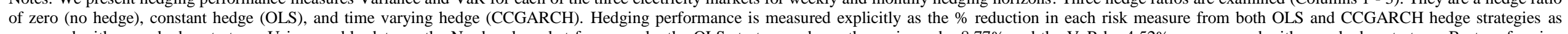

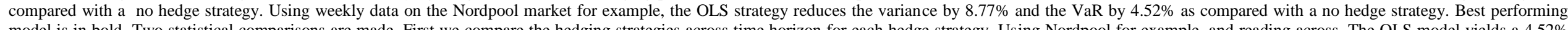

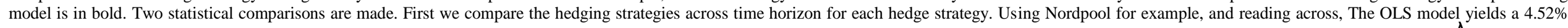

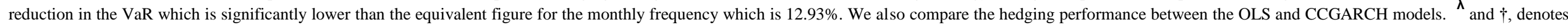
significance at the $5 \%$ and $10 \%$ levels for and weekly vs. monthly comparisons respectively.* and **denotes significance at the 5\% level and $10 \%$ levels for OLS model vs CCGARCH model comparison. 
We also compare the hedging performance of the OLS and CCGARCH models using a bootstrap process ${ }^{15}$ whereby we resampled the hedged returns from each portfolio to facilitate t-tests of the differences between the performances of the different hedging models. The models generated significantly different performance for APXUK and Phelix at the weekly frequency and for Nordpool and Phelix at the monthly frequency. The differences were especially marked for the Phelix market which yielded very large performance differentials depending on the model used to estimate the OHR. In terms of the best model, the OLS was the better performer in all cases at the weekly frequency and also performed best in $50 \%$ of cases at the monthly frequency. In those cases where the CCGARCH model outperformed the OLS model, there was a significant difference only in the case of the Nordpool hedge at the monthly frequency. The relatively poor performance of the CCGARCH model may relate to an inability of GARCH models to handle large and frequent jumps in the basis as are typical for electricity markets. This has been found by other studies for even less volatile series such as Oil (Alexander, Prokopczuk and Sumawong, 2013) and Equities (Lee and Yoder, 2007). From these results we conclude that an OLS model is perfectly adequate in that it provides the best chance of obtaining good hedging effectiveness.

Next we formally compare the performance of the different markets in Table 4 using both Variance and VaR metrics on a model by model basis. Taking Monthly data as an example and using the Variance as our risk metric we can see that there is a significant difference of $7.13 \%$ (t-stat 8.78 ) between the hedging performance of the Nordpool and APXUK markets using the OLS model. Overall we make 24 comparisons. Of these there are significant differences between the hedging performances of the different electricity markets in $67 \%$ of cases. This indicates that

\footnotetext{
${ }^{15}$ See Efron (1979)
} 




Note: Table 4 shows a comparison between the hedging performance for the different electricity markets. Taking Monthly data for example, there is a significant difference $(7.13 \%)$ between the hedging performance of the OLS model for the Nordpool and the APXUK markets. T-statistics are in parentheses. ${ }^{*},{ }^{* \star}$ denotes significance at the $5 \%$ and $10 \%$ levels respectively. 
futures tend to work better as a hedging tool depending on the market they are based on.

\section{Rolling Window Portfolio Results}

Our initial estimates from the OLS and CCGARCH models for hedging effectiveness indicated relatively poor performance. To investigate this further we generated a series of rolling window OHR's together with a time dependent hedging effectiveness measure to allow us to track hedging performance in the different markets through different time periods. Results for this estimation are presented in Table 5 and in Figure 4. The most noteworthy point is that there is a large variation in the hedging effectiveness across time. For certain time periods, hedges are quite effective and in some cases comparable to other energy markets. This is particularly the case for the monthly hedging frequency and for the Nordpool market which shows a maximum \% reduction in the variance of $82.9 \%$. For APXUK it is $72.3 \%$ and for Phelix it is $64.3 \%$.

\begin{tabular}{cccc}
\hline & $\begin{array}{c}(1) \\
\text { NORDPOOL }\end{array}$ & $\begin{array}{c}(2) \\
\text { PPXUK }\end{array}$ & $\begin{array}{c}(3) \\
\text { PHELIX }\end{array}$ \\
\cline { 2 - 4 } WEEKLY & $13.3 \%$ & $7.9 \%$ & $11.3 \%$ \\
MEAN & $0.1 \%$ & $0.0 \%$ & $0.1 \%$ \\
MAX & $43.8 \%$ & $25.2 \%$ & $33.4 \%$ \\
STDEV & $11.2 \%$ & $4.9 \%$ & $7.4 \%$ \\
MONTHLY & & & $24.3 \%$ \\
MEAN & & & $1.0 \%$ \\
MIN & $39.2 \%$ & $20.6 \%$ & $64.3 \%$ \\
MAX & $0.0 \%$ & $0.0 \%$ & $14.3 \%$ \\
STDEV & $82.9 \%$ & $72.3 \%$ & $19.8 \%$ \\
\hline
\end{tabular}

Table 5: Hedging Effectiveness of Portfolio of Rolling Window OHR's

Summary statistics of the hedging effectiveness of a portfolio of hedges estimated using a rolling window based on variance minimisation. 



Fig.4 Time Varying Hedging Rolling Window Portfolio OHR's and Hedging Effectiveness.

These figures would constitute reasonably effective hedges for any asset, however as shown in Figure 4, there are also periods for which there is no appreciable benefit to hedging.It would appear therefore that hedges only seem to be effective for short time periods during which the spot and futures returns are highly correlation. However, the fundamentally volatile nature of electricity markets means that this is a relatively rare occurrence and of course is difficult to predict. 
Table 6 reports the out-of-sample results which are based on a one step-ahead forecast of the OHR's as described in section 4.As for the in-sample results, the hedging effectiveness is generally low. We can also see that in some cases hedging yields an increase in risk as compared with a no-hedge scenario. For example, a CCGARCH hedge at the weekly frequency marginally increases the variance of a Nordpool position from $1.60 \%$ to $1.67 \%$. Also the out-of-sample results confirm the finding that monthly hedges significantly outperform weekly hedges. Finally the results show that the hedging efficiency for the in sample period is generally higher than for the out-of-sample period. Across all markets, models and both risk metrics, the in-sample average hedging effectiveness is $1.6 \%$ higher at the weekly frequency and $4.4 \%$ higher at the monthly frequency. Given the results of our rolling window portfolio estimation which showed a wide variation in hedging effectiveness, we attribute this difference to the time period examined. 


\begin{tabular}{|c|c|c|c|c|c|c|c|}
\hline & & 1 & 2 & 3 & 4 & 5 & 6 \\
\hline & & \multicolumn{3}{|c|}{ WEEKLY } & \multicolumn{3}{|c|}{ MONTHLY } \\
\hline & & NO HEDGE & OLS & CCGARCH & NO HEDGE & OLS & CCGARCH \\
\hline \multirow[t]{4}{*}{ NORDPOOL } & VARIANCE & $1.60 \%$ & $1.61 \%$ & $1.67 \%$ & $3.94 \%$ & $3.30 \%$ & $3.27 \%$ \\
\hline & VaR & $-€ 292,168$ & $-€ 293,653$ & $-€ 298,790$ & $-€ 454,238$ & $-€ 411,451$ & $-€ 405,111$ \\
\hline & $\%$ Variance Reduction & $0.00 \%$ & $-0.45 \% *^{\lambda}$ & $-3.92 \%^{\wedge}$ & $0.00 \%$ & $16.31 \%$ & $17.10 \%$ \\
\hline & $\%$ VaR Reduction & $0.00 \%$ & $-0.51 \% *^{\lambda}$ & $-2.27 \%^{\lambda}$ & $0.00 \%$ & $9.42 \% *$ & $10.82 \%$ \\
\hline \multirow[t]{4}{*}{ APXUK } & VARIANCE & $1.46 \%$ & $1.38 \%$ & $1.36 \%$ & $2.82 \%$ & $2.40 \%$ & $2.57 \%$ \\
\hline & VaR & $-€ 282,349$ & $-€ 275,671$ & $-€ 272,936$ & $-€ 391,726$ & $-€ 363,695$ & $-€ 373,904$ \\
\hline & $\%$ Variance Reduction & $0.00 \%$ & $5.33 \% *^{\lambda}$ & $6.66 \% \dagger$ & $0.00 \%$ & $14.78 \% *$ & $8.85 \%$ \\
\hline & $\%$ VaR Reduction & $0.00 \%$ & $2.37 \% \dagger$ & $3.33 \%$ & $0.00 \%$ & $7.16 \% *$ & $4.55 \%$ \\
\hline \multirow[t]{4}{*}{ PHELIX } & VARIANCE & $13.52 \%$ & $12.34 \%$ & $12.20 \%$ & $27.86 \%$ & $25.01 \%$ & $25.40 \%$ \\
\hline & VaR & $-€ 857,703$ & $-€ 816,565$ & $-€ 810,242$ & $-€ 1,205,944$ & $-€ 1,133,608$ & $-€ 1,141,122$ \\
\hline & $\%$ Variance Reduction & $0.00 \%$ & $8.79 \% *$ & $9.80 \%$ & $0.00 \%$ & $10.22 \% * *$ & $8.82 \%$ \\
\hline & $\%$ VaR Reduction & $0.00 \%$ & $4.80 \%$ & $5.53 \%$ & $0.00 \%$ & $6.00 \%$ & $5.38 \%$ \\
\hline
\end{tabular}

\section{Table 6: Out-of-Sample Hedging}

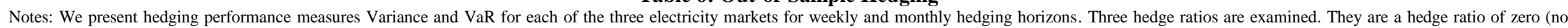

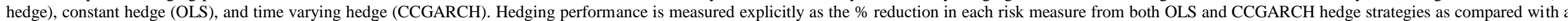

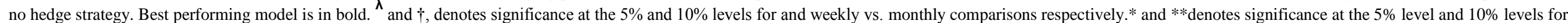
OLS model vs CCGARCH model comparison. 


\section{Conclusion}

We examine the volatility characteristics of three of Europe's most deeply established electricity markets and estimate risk management strategies for those markets using futures hedging. We look at two different hedging horizons and apply both constant and time varying approaches. We also a two sided risk measure - the variance as well as a downside risk measure - VaR to evaluate the hedging effectiveness of these hedge strategies. We also track the conditional hedging performance over a time period spanning 2005 - 2014 which allows us to make a comprehensive comparison of the relative hedging performance of the different market through different market conditions.

Our findings indicate that there are significant differences between the volatility characteristics, OHR's and the hedging performance for the different energy markets we examine.We also find that the time period and underlying volatility characteristics of the electricity market have a very significant impact on the hedging efficacy. Of particular note is the poor hedging performance of electricity hedges for all markets at the weekly frequency. The implication of this is that electricity market participants may struggle to reduce their exposure using futures hedging over short time horizons. The relatively poor performance of electricity futures as risk management tools raises questions as to the role and utility of electricity futures markets

\section{Acknowledgements}

This study was supported by a College of Business Research Fellowship from Dublin Institute of Technology. We thank seminar participants at the Dublin Energy Lab Symposium 2014 for helpful comments. 


\section{References}

Alexander, C., Barbossa, A., 2008. Hedging index exchange traded funds. Journal of Banking Finance, 32, 326-337.

Alexander, C., Prokopczuk, M., Sumawong, A., 2013.The (de)merits of minimumvariance hedging: Application to the crack spread. 36, $698-707$.

Bollerslev, T., 1990. Modeling the coherence in short-run nominal exchange rates: A multivariate generalized ARCH model. Review of Economics and Statistics, 72, 498505.

Botterud, A., Kristiansen, T., llic, M., 2010.The relationship between spot and futures prices in the Nord Pool electricity market. 32, 5, 967-978.

Bystrom, H., 2003. The hedging performance of electricity futures on the Nordic power exchange.Applied Economics, 35, 1-11.

Brinkmann. E., Rabinovitch. R., 1995. Regional limitations on the hedging effectiveness of natural gas futures. The Energy Journal,16, 113-124.

Brooks, C., Chong, J., 2001. The cross-currency hedging performance of implied versus statistical forecasting models. Journal of Futures Markets, 21, 1043-1069.

Chang, C., McAleer, M., Tansuchat, R., 2011. Crude oil hedging strategies using dynamic multivariate GARCH. Energy Economics, 33, 912 - 923. 
Cotter, J., Hanly, J. 2006. Re-examining hedging performance. Journal of Futures Markets, 26, 657-676.

Cotter, J. Hanly, J. 2012. A utility based approach to energy hedging. Energy Economics, 34, 817 - 827.

deVilledeGoyet, C., Dhaene, G., \&Sercu. P., 2008.Testing the martingale hypothesis for futures prices: implications for hedgers. Journal of Futures Markets, 28, 1040 1065.

Ederington, L., 1979. The hedging performance of the new futures markets. Journal of Finance, 34, $157-170$.

Efron, B., 1979. Bootstrap methods: Another look at the Jack-knife. The Annals of Statistics, 7, 1-26.

Frestad, D., 2012. Liquidity and dirty hedging in the Nordic electricity market. Energy Economics, 34, 5, $1341-1355$.

Gianfreda, A., 2010. Volatility and Volume Effects in European Electricity Spot Markets. Economic Notes, 39: 47-63.

Harris, R., Shen, J., 2006. Hedging and value at risk. Journal of Futures Markets, $26,4,369-390$. 
Johnson, L., 1960. The theory of hedging and speculation in commodity futures. Review of Economic Studies, 27, 139-151.

Jorion, P. 2006. Value at Risk. 3rd edn. New York: McGraw Hill.

Kroner, K., Sultan, J., 1993. Time-varying distributions and dynamic hedging with foreign currency futures. Journal of Financial and Quantitative Analysis, 28,4, 535551.

Lien, D., Yang, L., 2008. Asymmetric effect of basis on dynamic futures hedging: Empirical evidence from commodity markets. Journal of Banking and Finance, 32, $187-198$.

Park, T., Switzer, L. 1995. Bivariate GARCH estimation of the optimal hedge ratios for stock index futures: A note. Journal of Futures Markets, 15, 61 - 67.

Root, T., Lien, D., 2003. Can modelling the natural gas futures market as a threshold cointegrated system improve hedging and forecasting performance? International Review of Financial Analysis.12, 2, 117-133.

Sanda, G., Olsen, E., Fleten, S., 2013. Selective hedging in hydro-based electricity companies. Energy Economics, 40, 326-338

Switzer, L., El-Khoury, M., 2007. Extreme volatility, speculative efficiency, and the hedging effectiveness of the oil futures markets. Journal of Futures Markets, 27, 1, $61-84$. 
Tanlapco, E., Lawarrée, J., and Liu, C. Hedging With Futures Contracts in a Deregulated Electricity Industry. IEEE Transactions on Power Systems, 17, 3, 577 582.

Wickens, S., Wimschulte, J., 2007. The pricing of electricity futures: evidence from the European energy exchange. Journal of Futures Markets, 27, 4, 387-410.

Wu, F., Guan, Z., Myers, R., 2011. Volatility spillover effects and cross hedging in corn and crude oil futures. Journal of Futures Markets. 31, 11, 1052-1075.

Xiao, Y., Colwell, D., Bhar. R., 2007. Risk Premium in Electricity Prices: Evidence from the PJM Market. Journal of Futures Markets, 00, 0, 1-18.

Zanotti, G., Gabbi, G., Geranio, M., 2010. Hedging with futures: Efficacy of GARCH correlation models to European electricity markets. Journal of International Financial Markets, Institutions and Money. 20, 135-148. 